\title{
Leaders or Managers to the Army
}

\author{
Milan Sopóci, Zdzislawa Dacko Pikiewicz \\ Academy of Business in Dabrowa Górnicza, Dabrowa Górnicza, Poland
}

\begin{abstract}
In recent years, the status of leaders has been highlighted and their role has been often overstated. The aim of the contribution is to show that in conditions of the armed forces, the role and the competence of the manager are often more important than competence of a leader. On the basis of the experience of the authors and more experienced officers, and by means of methods of targeted interviews and discussions, the areas have been identified where management capabilities are more important than leadership capabilities. More than 30 experienced officers have contributed their views on the presented results. There are areas, such as strategy, environment, organizational culture, external and internal changes, efficiency, and results and performance. In conclusion, authors suggested solution for nomination of leaders and managers to command positions.
\end{abstract}

Keywords: leaders and managers skills, competences, targeted interview, discussion, experience, command positions, officers

\section{Introduction}

The army needs leaders, such is the requirement of the times and the military college has to bring up leaders and prepare them for the officer positions. For these reasons, this paper does not speak about preparation of commanders as the authors used to be at the Armed Forces Academy, but about the preparation of cadets-leaders. As the tasks and requirements are known to commanders, leadership capabilities are not always appropriate for their optimal fulfillment. The aim should be to find out the requirements for graduates of military schools from experienced commanders and to identify areas where the graduates with leadership orientation and where the graduates with management orientation can work. In the course of the study, they would be able to strengthen the knowledge-based management subjects, such as management, management communication, and operational analysis on one hand; leadership subjects, such as leadership, command and control, and decision-making processes, on the other hand. In order to command the army, it would mean the ability to make the most of the competence of each graduate.

\section{Requirements for an Officer-The Military College Graduate}

In recent years, it is a requirement that a modern military commander is the skilled manager and leader, is eligible to perform his duties, and is able to manage processes and personnel. In general, the greater emphasis is put upon management and leadership education at the military academies than on gaining knowledge on tactics,

Milan Sopóci, Ph.D., Col. (ret.). professor, Academy of Business in Dąbrowa Górnicza, Dabrowa Górnicza, Poland; Armed Forces Academy of gen. M. R. Štefánik in Liptovský Mikuláš, Slovakia.

Zdzislawa Dacko Pikiewicz, Ph.D., associate professor, Academy of Business in Dabrowa Górnicza, Dabrowa Górnicza, Poland.

Correspondence concerning this article should be addressed to Milan Sopóci, Armed Forces Academy of gen. M. R. Štefánik in Liptovský Mikuláš, Demänová 393, 03101 Liptovský Mikuláš, Slovakia. 
training, and military thinking on the battlefield. Requirements for their training and competence which they have to dispose are listed in various materials, e.g., the standpoint of the Chief of General Staff of Armed Forces of the Slovak Republic is referred to in the reference requirements on training cadets and future officers (General Staff of Armed Forces, 2008). These represent a wide range of capabilities in the field of management, leadership, legal and economic maturity, technical proficiency, language skills, and the physical and mental fitness. Commanders in the role of manager and leader are encouraged to gain:

- the ability of an independent decision-making and to take responsibility for their decisions;

- the ability of creative interdisciplinary thinking, constructive criticism, and communication within team;

- the ability to reach consensus in teamwork;

- the ability to use the results of scientific research and formulate their own assessment of the problem.

Some management and leadership theorists claimed that leadership is not a scarcity and thus can be learned. However, such a claim is disputable. Even the recent research (e.g., University of Michigan) taking a sample of successful leaders shows that only about $20 \%$ of the leadership ability can be obtained by studies, while up to $80 \%$ of capabilities are innate abilities and skills acquired by experience. The truth is somewhere in between. The following graph displays the simplified training process of a leader (Figure 1).

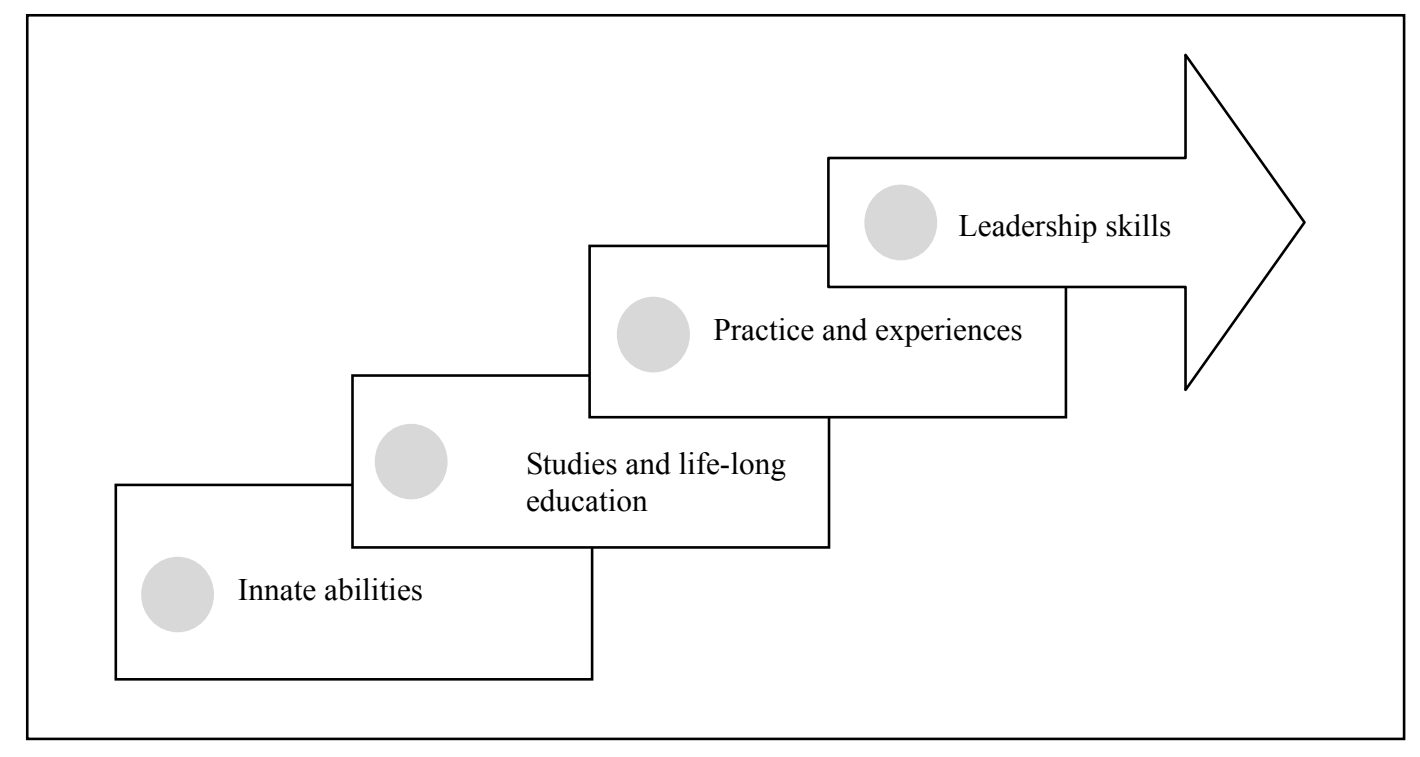

Figure 1. Leadership process.

Other armies have similar requirements on leader's capabilities, e.g., requirements on a leader in the US army after graduating a college are as follows (Townsend \& Gebhardt, 1997):

- demonstrating the ability to apply leadership theory in practice as a commander;

- demonstrating moral and ethical development;

- demonstrating the ability to command and manage others;

- demonstrating the ability to work and communicate as commander at both the vertical and horizontal levels;

- demonstrating the ability to work as an effective team member;

- respecting each co-worker, who participates in carrying out the tasks;

- demonstrating the decision-making ability; 
- demonstrating the ability to communicate;

- demonstrating the ability to self-improve in terms of leadership;

- demonstrating to describe one's personal improvement in terms of leadership.

American prescription field manual FM-22-100 (Department of the Army, 1999) integrates followings among the leadership competencies - keeping on top of the things, communicativeness, ability to learn and to consult, the team creation, decision making, planning, technical and tactical skills, use of available systems, and professional ethics.

All these definitions are the result of research, knowledge, and experience of major military theorists, as well as commanders with extensive experience. It may therefore be assumed that if the commander (officer, a professional soldier) has the skills mentioned above, he will be eligible to become a successful leader.

Therefore, both categories can be rated positively. Why, then, are the leaders so admired? Are they really so brilliant? The initial euphoria of leadership, which culminated in the 1970s, started to fade at the end of the century. Even the creators of the leadership theory began to point out the dangers of overestimating the role of leaders at the expense of managers. Maxwell (2002) questioned the role of leaders in his regular column in "against the leaders":

- The leaders are really less important than you think;

- Leaders are only as good as the situation in which they are required;

- Leaders often manipulate people and if they are not controlled, they can often derail the entire organization from the right direction;

- Leaders do not appeal to extremely creative and educated people;

- The bigger is the participation of management, the lesser is the need for leaders.

\section{Approach of Managers and Leaders to Different Military Scopes}

The fact that leadership capabilities are not always convenient for management personnel at certain levels of management is proved, when is compared to the position of managers and leaders in terms of the environment, strategy, organizational culture, external and internal changes, effectiveness, results, and performance. Mentioned areas have been identified on the basis of consultations, discussions, and targeted interviews with experienced commanders who perform important command and staff functions (Figure 2).

Any organization in terms of the Armed Forces of the Slovak Republic, any brigade, or regiment can be characterized, according to the environment as an organization dominated by management or leadership. Generally, the characteristic is determined and depends on the commander or a chief of staff. Each organization has its advantages and disadvantages. Organization dominated by management is characterized by clear objectives, priorities, structures, and processes. On one hand, it has difficulties to cope with changes and to adapt to the new situation. On the other hand, organizations dominated by leaders have the ability to change, innovate, and create the disadvantage that it has difficulties to create a stable environment necessary for carrying out the given tasks. Specific environment can be described as an environment focused on conflicts. The tasks of managers and leaders are similar to fight for their position and beliefs. In order to gain a dominant position, con-tricks are often used as an accompanying feature of the struggle, the age-old rivals and enemies join forces and the competing groups are created within a single unit. There are known cases of competition between the commander and chief of staff within the army that had to be handled formally as they reduced the efficiency of the whole unit (Figure 3). 
Approaches of managers and leaders in terms of strategy are very different especially, when it is necessary to accurately determine the direction of development and also personnel, financial, and material resources for their organization. It can simply mean that while managers monitor options, leaders concentrate on goals (visions).

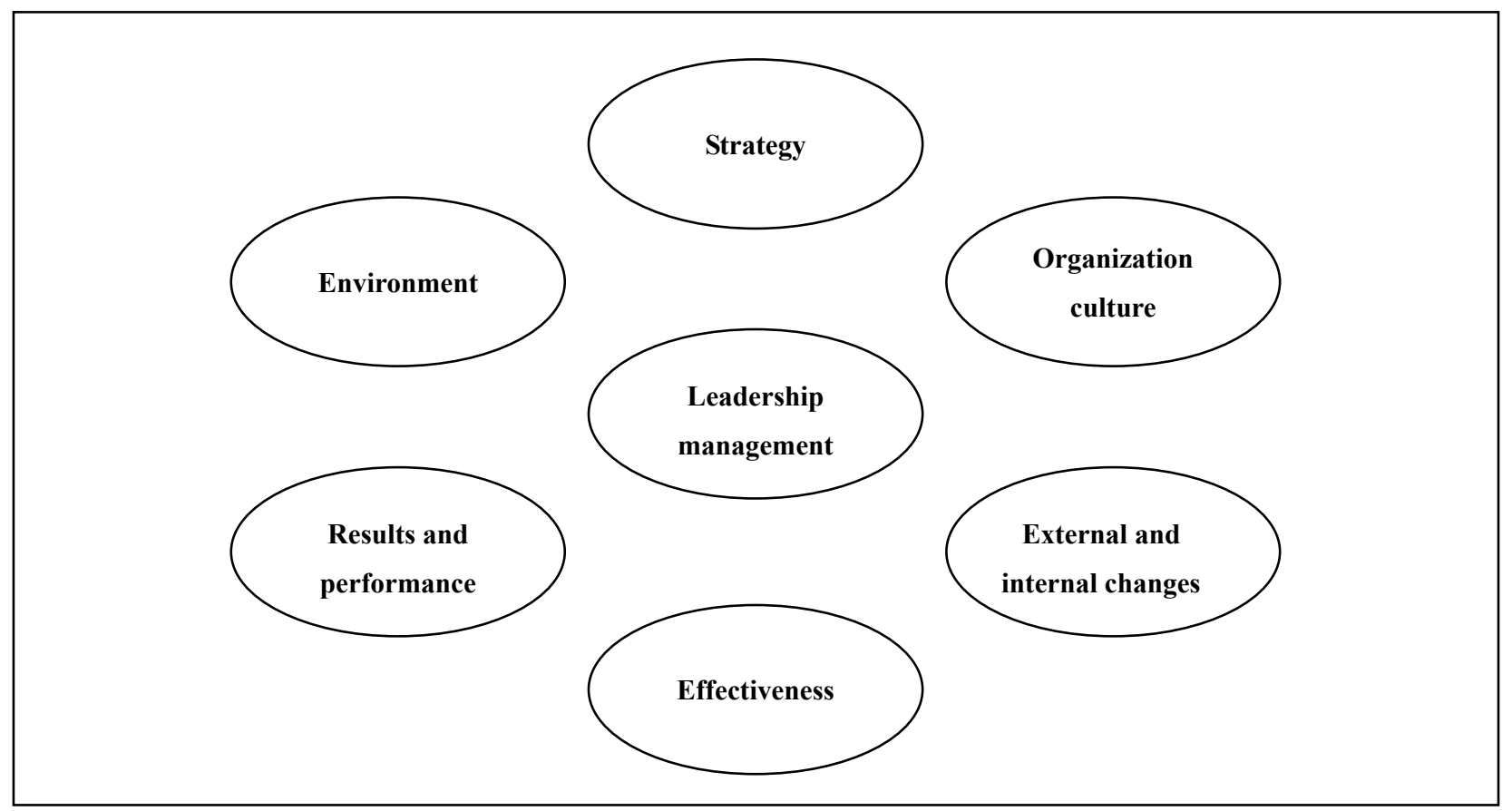

Figure 2. Areas with different approach of managers and leaders.

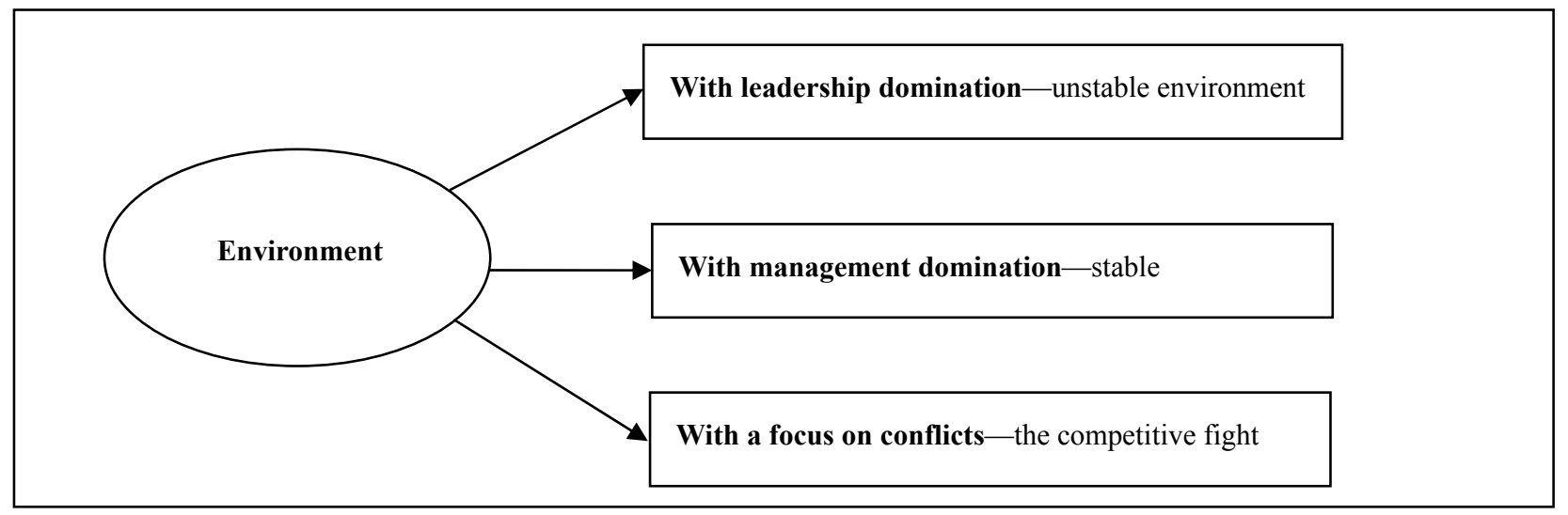

Figure 3. Assessment of the environment in terms of the stability.

Leaders are able to point out a final goal, but often they are not able to answer a simple question of how to achieve it or they leave this task to managers to cope with it. If it does not work out, most leaders suggest trying new option. But it can be very dangerous in terms of armed forces, because, e.g., in the fight, there may no longer be other option, or as in the case of military education, the option to provide education for civilians concentrating on civilian subjects resulted in the complete collapse of military education of Armed Forces Academy and returned it a few years back in terms of development. When determining the strategic direction, managers try to find weaknesses of the organization as well as competition and to gradually improve their 
position, whereas, leaders build on the strengths and they try to develop them further. When planning the operations within the armed forces, probably the most important task is a thorough analysis of its own forces as well as enemy forces, determination of the resources and forces ratio, and evaluation of combat operations methods (Hickman, 1995). These will always be the most relevant information for the commander's decision. Making a decision based only on its own quality and own strengths could be an unpleasant surprise. Arab armies could see that for themselves in the war against Israel in 1967, when they overestimated the number of their forces and resources and underestimated the morale approach, flexibility, and creativity of the Israeli army (Figure 4).

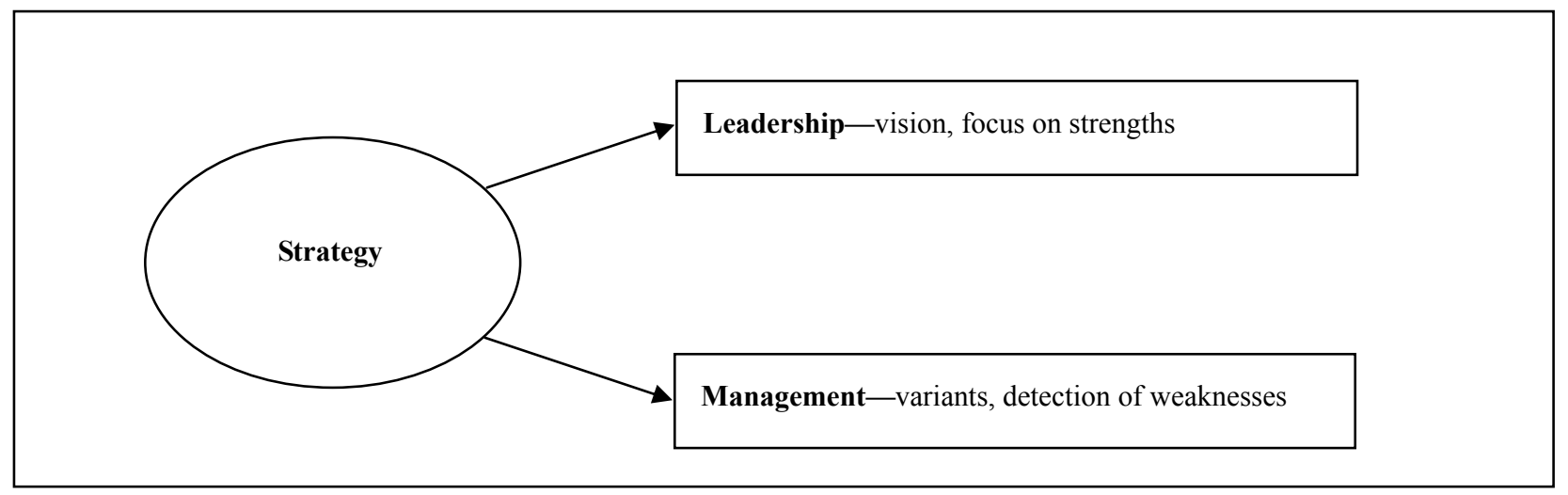

Figure 4. Different approaches of managers and leaders in terms of strategy.

In terms of organizational culture, the attitude of managers and leaders towards the evaluation of labor standards and practices is interesting. Even the supporters of leadership agree that standards should be questioned, but never ignored. It means that standards are important but should not be too specific. It is necessary to establish certain criteria for evaluating people, processes, and outcomes, but it should also avoid wasting the time by looking for and exploring new employment standards and processes. In the conditions, often "innovations" in form of implementing new forms, reports, criteria, or updating older standards, is not because it is necessary for the operation of the organization, but to confirm the importance and necessity of a particular staff member.

In terms of external and internal changes, the most significant differences can be seen in management and leadership orientation. While managers try to achieve stability of organizations, leaders constantly try to introduce changes and explore new directions, procedures, priorities, and programs. In case, there are no boundaries set for their activities and they have sufficient powers; they can easily induce a state of permanent crisis within the organization, as can be seen at an example of the military education. Finally, leaders often overlook and disparage the functional directions, priorities, and tasks. While managers often see things more complicated than they really are, leaders in their effort to reach the specific objective as soon as possible simplify the reality. In armed conflict, it can lead to underestimating of the enemy or the overestimating their own forces and capabilities and thus convincing themselves to expect easy victory (Figure 5).

Individual efficiency is another area where the leader should not play a positive role. Managers on one hand try to take responsibility for the people and situations, because they believe that the organization expects them to do so. Leaders, on the other hand, like to pass the responsibility to others. This could, in practice, mean that the leader-commander would make a decision to carry out the operation based on the options, but 
responsibility for its implementation and mainly a result would be up to his subordinates. It can easily guess what this could mean in the case of a positive or negative outcome of operations for one or the other side of the conflict. During the Second World War, the failure was often punished by shooting the commander in charge. Similar results can be expected even in cases when the competence and responsibility are passed to the others too soon or are taken too soon. Such a situation arose within the air defense of ground troops during the rearmament of the new modern rocketry. Young and ambitious leaders got the opportunity to prove that they are the right people at the right place and in the attempt to prove this, so they were helter-skelter changing the nature of the unit, regardless of the consequences. This competition has grown into a serious conflict, not only within the unit environment, but also resulted in an open fighting amongst them. The situation became so serious that personnel actions had to be taken.

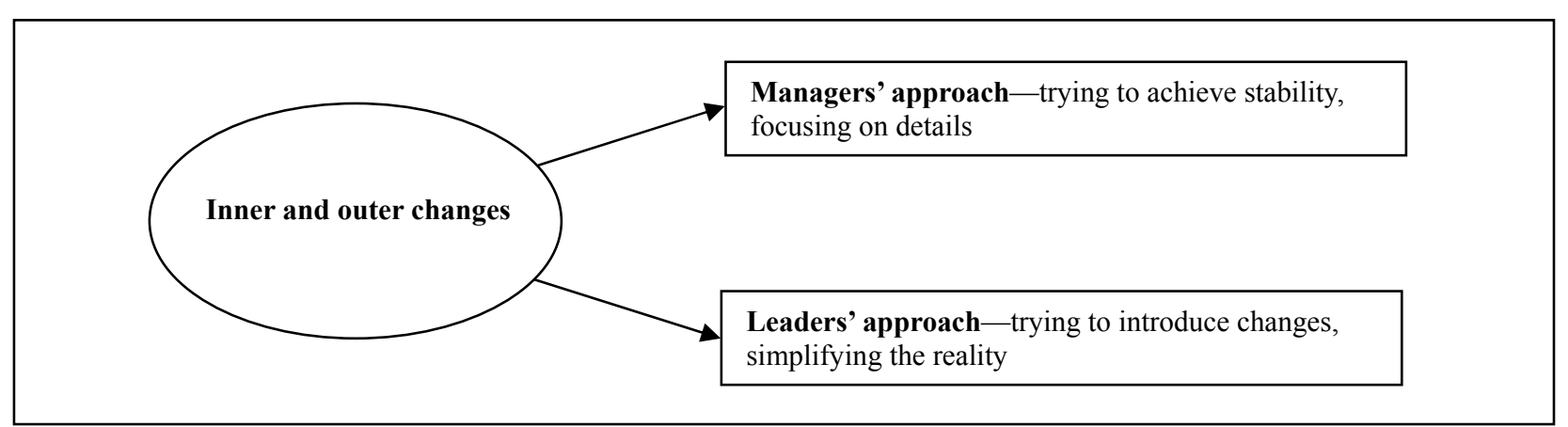

Figure 5. Managers' and leaders' approach in terms of inner and outer changes.

The difference is in managers' and leaders' approach to their responsibilities. While managers perform their duties, leaders follow their ideals. No organization, let alone armed forces and its individual components, can live from their ideals actions and success. Focusing on the ideals and neglecting the duties must inevitably lead to failure of not only the managers but also the entire organization. Responsibilities are very important, particularly because they allow to implement the dreams and ideals.

Areas of efficiency and the results are almost always associated with success or failure of an organization or individual. In the future, it will probably be the same. While managers have the tendency to incline towards the efficiency, leaders incline towards the potential. Each commander would probably prefer subordinate - manager whose efforts have good results for their leaders who may have a dormant potential, but their results are worse than those of the first category. The results of the exercises, exams, and firing are not about the future but about the present (Figure 6).

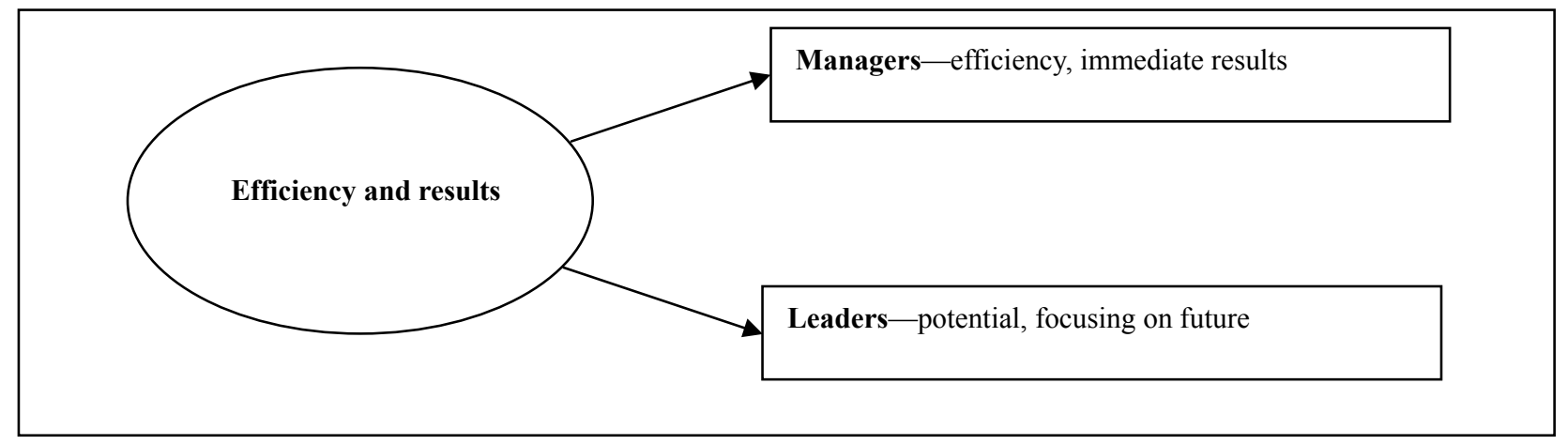

Figure 6. Area of efficiency and results at the position of manager and leader. 
Good results can bring career promotion on one hand, while bad results, on the other hand, can mean stagnation or nowadays even the end of career. From the perspective point of view, managers focus on short-term results, whereas leaders focus on long-term results. From this perspective, commanders-leaders should be at the higher levels of command positions, as they are able to predict the development and determine the direction of development in the controlled area. At the tactical level where it is necessary to show immediate results and to fulfill combat tasks, exercises, or life-firing, it is preferable to employ a manager. These are usually the positions offered to the young graduates of the schools.

\section{Conclusions}

By no means can it be affirmed that it is necessary to change the subject of education from preparing the managers instead of leaders. However, if top management of schools does not want to make mistakes and deal with such problems as mentioned in paragraphs above as examples in different areas of responsibilities of managers and leaders, it must not focus cadets training to just leaders training. Optimally functioning organizations, environment, and people are balanced and integrated and they value both leadership and management. Long-term perspective requires compliance of management and leadership. Such cooperation releases the natural tension between managers and leaders and provides coordination of all major activities on a stable basis. It leads people to appreciate the different procedures and specializations; successfully face tough conditions cope with the problems and openly communicate with each other in the work environment, where the balance and integration would be the result of understanding, recognition, and compliance (Hickman, 1995). It is only when people understand themselves, their strengths and weaknesses and approaches, when they can recognize and appreciate the approaches of others. Only if they can develop a process of open and honest communication, they can allow people to understand others as they wish to be understood. It needs such a balanced and integrated environment more than ever before to be able to successfully overcome the situations within organizations that are consequences of a global crisis.

It is known that management and leadership elements interrelate (Sadler, 2003). Therefore, it would be the best for the Armed Forces, if a graduate of the Armed Forces Academy would master the necessary management and leadership skills: Management skills he could use at the beginning of the career at the tactical level and the leadership skills he could use later in the career especially at the higher command positions. Maybe it would be better not to talk about the preparation and training of leaders and managers, but as it was accustomed to before and it also describes the category better- to prepare and train commanders.

\section{References}

Department of the Army. (1999). Military leadership (Field manual FM-22-100). Washington DC: U.S. Government Printing Office.

General Staff of Armed Forces. (2008). Reference requirements on training cadets and future officers. Bratislava: Ministry of Defense Printing Office.

Hickman, C. R. (1995). Managers and leaders. Bratislava: Open Windows.

Maxwell, J. C. (2002). Leadership. Gabal: Offenbach.

Sadler, P. (2003). Leadership. London: Kogan Page.

Townsend, P. L., \& Gebhardt, J. E. (1997). Five-star leadership. New York: John Wiley \& Sons. 